pulmonary disease and neoplasms vs biologic-naïve pts. Most biologic-failure pts (96.7\%) had previously received $\geq 1 \mathrm{TNF}$ inhibitor (TNFi): $48.7 \%$ had received 1 and $48.0 \% \geq 2$ TNFi; $56.6 \%$ had received $\geq 2$ bDMARDs. The overall 2-year retention rate was $47.9 \%$ and was higher for biologic-naïve vs biologic-failure pts ( 54.5 vs $45.2 \% ; p<0.001$ ); the most common reasons for $A B A$ discontinuation were inefficacy (61.4 vs $67.7 \%$ ) and safety (21.3 vs $21.2 \%$ ). In pts who discontinued ABA, $83.0 \%$ started a bDMARD $\leq 6$ months after discontinuation (Table), most commonly ABA IV. Mean (SD) days from stopping ABA to starting a bDMARD was similar for biologic-naïve (93.4 [51.3]) and biologic-failure pts (93.6 [48.0]). Among pts who restarted ABA, 62 (80.5\%) biologic-naïve and 158 $(85.0 \%)$ biologic-failure pts were considered to have discontinued as the time from last dose was $>84$ (IV) or $>28$ (SC) days, and thus were no longer temporary discontinuations, as predefined in the protocol. Three pts discontinued for bad compliance, 3 for lack of efficacy, 3 for remission/major improvement, 12 for safety and 15 for surgery. A good/moderate EULAR response was achieved by $76.7 \%$ of pts at the last follow-up before ABA discontinuation and $58.3 \%$ at ABA restart; mean (SD) DAS28 (CRP) was $3.2(1.1)$ and $3.8(1.4)$, respectively.

\begin{tabular}{|c|c|c|c|}
\hline & \multicolumn{2}{|c|}{$\begin{array}{c}\text { bDMARD } \leq 6 \text { months after } \\
\text { ABA discontinuation }\end{array}$} & \multirow{2}{*}{$\begin{array}{c}\text { bDMARD prior to initial } \\
\text { ABA treatment in pts who restarted ABA } \\
\text { Biologic failure } \\
n=186\end{array}$} \\
\hline & $\begin{array}{c}\text { Biologic naïve } \\
n=186\end{array}$ & $\begin{array}{c}\text { Biologic failure } \\
n=526\end{array}$ & \\
\hline None & 35 (18.8) & $86(16.3)$ & \\
\hline Abatacept & 77 (41.4) & $186(35.4)$ & - \\
\hline IV & 71 (38.2) & 170 (32.3) & \\
\hline SC & $6(3.2)$ & $16(3.0)$ & \\
\hline TNFi & $41(22.0)$ & 74 (14.1) & $181(97.3)$ \\
\hline Adalimumab & $10(5.4)$ & $12(2.3)$ & $108(58.1)$ \\
\hline Etanercept & $13(7.0)$ & $21(4.0)$ & $125(67.2)$ \\
\hline Infliximab & $7(3.8)$ & $13(2.5)$ & $55(29.6)$ \\
\hline Certolizumab & $7(3.8)$ & $17(3.2)$ & $5(2.7)$ \\
\hline Golimumab & $4(2.2)$ & $11(2.1)$ & $2(1.1)$ \\
\hline Other bDMARD & 33 (17.7) & $180(34.2)$ & $51(27.4)$ \\
\hline Anakinra & $1(0.5)$ & $4(0.8)$ & $5(2.7)$ \\
\hline Rituximab & $6(3.2)$ & $58(11.0)$ & $30(16.1)$ \\
\hline Tocilizumab & $26(14.0)$ & $\begin{array}{l}118(22.4) \\
\text { Data are n (\%) }\end{array}$ & $21(11.3)$ \\
\hline
\end{tabular}

Conclusions: Prior to abatacept treatment, over half of biologic-failure pts had received $\geq 2$ bDMARDs and most had received a TNFi. After initial discontinuation (protocol defined), over one-third of pts restarted abatacept.

Disclosure of Interest: R. Alten Grant/research support from: Bristol-Myers Squibb, Speakers bureau: Bristol-Myers Squibb, H.-M. Lorenz Consultant for: AbbVie, Bristol-Myers Squibb, Roche-Chugai, UCB, MSD, GSK, SOBI, Medac, Novartis, Janssen-Cilag, AstraZeneca, Pfizer, Actelion, Speakers bureau: AbbVie, Bristol-Myers Squibb, Roche-Chugai, UCB, MSD, GSK, SOBI, Medac, Novartis, Janssen-Cilag, AstraZeneca, Pfizer, Actelion, X. Mariette Grant/research support from: Biogen, Pfizer, UCB, Consultant for: Bristol-Myers Squibb, LFB, Pfizer, GSK, UCB, H. Nüßlein Consultant for: AbbVie, Bristol-Myers Squibb, Celgene, Janssen, Lilly, MSD, Novartis, Pfizer, Roche, Speakers bureau: AbbVie, Bristol-Myers Squibb, Celgene, Janssen, Lilly, MSD, Novartis, Pfizer, Roche, M. Galeazzi: None declared, F. Navarro Grant/research support from: Pfizer, MSD, AbbVie, Bristol-Myers Squibb, Roche, Consultant for: Pfizer, MSD, Roche, UCB, AbbVie, Bristol-Myers Squibb, Jansen, Lilly, Speakers bureau: Pfizer, MSD, Roche, UCB, AbbVie, Bristol-Myers Squibb, M. Chartier Employee of: Bristol-Myers Squibb, Y. Elbez: None declared, C. Rauch Shareholder of: Bristol-Myers Squibb, Employee of: Bristol-Myers Squibb, M. Le Bars Shareholder of: Bristol-Myers Squibb, Employee of: Bristol-Myers Squibb

DOI: 10.1136/annrheumdis-2017-eular.1392

\section{AB0268 ACPA SEROPOSITIVITY AND PERIPHERAL NATURAL KILLER CELLS AS PREDICTIVE MARKERS OF CLINICAL RESPONSE TO RITUXIMAB IN RHEUMATOID ARTHRITIS PATIENTS}

R.M. Ferreira, R. Fonseca, D.R. Gonçalves, F. Aguiar, T.M. Rocha, A. Bernardo, S. Pimenta, M. Bernardes, L. Costa. São João Hospital Centre, Porto, Portugal

Background: The efficacy of B cell-depletion therapy confirms the importance of $B$ lymphocytes in rheumatoid arthritis's (RA) pathogenesis. Rheumatoid factor (RF) and anti-citrullinated peptide antibodies (ACPA) are prognostic factors for a more severe disease. Others immune elements, namely natural killer (NK) cells, seems to influence RA clinical response to rituximab (RTX), but data are lacking. Objectives: To analyze the influence of baseline status/levels of RF, ACPA and serum immunoglobulin $\mathrm{G}(\mathrm{IgG})$ level in RTX treatment. To study the effect of RTX on NK and CD19+ cells in RA patients and their association with clinical response at 6,12 and 18 months $(M)$.

Methods: An observational retrospective study was conducted, including all the consecutive patients with diagnosis of RA under rituximab, followed at our Rheumatology department. Demographic and clinical data were obtained by consulting the national database (Reuma.pt) and the analysis was limited until december 2016. RF, ACPA and IgG titres were evaluated at baseline. NK (CD56+CD16+) and B lymphocytes (CD19+) absolute counts were assessed by flow cytometry prior to the first RTX cycle and $6 \mathrm{M}$ after. Clinical responses were assessed by DAS28 and EULAR criteria at 6,12 and $18 \mathrm{M}$. Correlations were studied using Spearman coefficient analysis (SPSS 20.0). Significance level was set as 0.05 .

Results: We included 63 RA patients (81\% of women), with a mean (SD) age of 61 (10) years and a mean disease duration of 19 (10) years, $86 \%$ RF-positive and $87 \%$ ACPA-positive. Bone erosions were present in $86 \%$ of the patients. At baseline, the mean DAS28 was 5.79 (1.55). Combination therapy with methotrexate or with others CDMARDs was used in $48 \%$ and $30 \%$ of the patients, respectively; RTX monotherapy in $22 \%$ of our sample. Thirty three patients were previously exposed to other biologics. The magnitude of response was greater in ACPA-positive vs ACPA-negative patients in terms of DAS28 variation at 6,12 and $18 \mathrm{M}$ (medians of 1.09 vs $-0.08 ; 2.03$ vs 0.35 and 2.10 vs $0.19 ; p=0.029, p=0.039$ and $p=0.004$, respectively), without significant differences between groups in terms of initial DAS28 $(5.91(1.60)$ vs $5.00(0.90), p=0.051)$. The presence of ACPA was also significantly associated with EULAR response at 6, 12 and $18 \mathrm{M}(64 \%, 75 \%$ and $85 \%$ in ACPA-positive patients vs $25 \%, 16 \%$ and $25 \%$ in ACPA-negative patients; $p=0.034, p=0.010$ and $p=0.001$, respectively). Outcomes did not differ according FR status. There were no associations between the values of FR, ACPA and IgG at baseline with the clinical response (DAS28 variation). CD19+ cells depletion occurred in all patients (mean of $146.4 / \mathrm{mm}^{3}$ at baseline vs $10.6 / \mathrm{mm}^{3}$ at $6 \mathrm{M}$ ). An increase of peripheral NK cells was seen at $6 \mathrm{M}$ (mean $231 \mathrm{~mm} / 3$ at baseline vs $289 / \mathrm{mm}^{3}$ at $6 \mathrm{M}$ ). We only have found a positive correlation between NK cells number at baseline and DAS28 variation at $6 \mathrm{M}$ $(r=0.35, p=0.023)$. There were no associations between, neither NK cells, nor CD19 cells variations at $6 \mathrm{M}$ with clinical response to RTX.

Conclusions: Our data suggest that ACPA seropositivity is associated with a better clinical response to RTX in RA patients. NK cells at baseline may be useful to identify early responders to RTX.

Disclosure of Interest: None declared

DOI: 10.1136/annrheumdis-2017-eular.4505

\section{AB0269 RAPID RADIOGRAPHIC PROGRESSION PROGNOSTIC FACTORS IN A LATIN AMERICAN COHORT OF RHEUMATOID ARTHRITIS}

R. Gamboa-Cárdenas ${ }^{1}$, M. Ugarte-Gil ${ }^{2}$, F. Zevallos-Miranda ${ }^{2}$

M. Medina-Chinchòn ${ }^{2}$, C. Elera-Fitzcarrald ${ }^{2}$, V. Pimentel-Quiroz ${ }^{2}$

J. Cucho-Venegas $^{2}$, O. Sarmiento-Velasquez ${ }^{2}$, C. Reàtegui-Solokova ${ }^{1}$,

J. Alfaro-Lozano ${ }^{2}$, Z. Rodriguez Bellido ${ }^{2}$, C. Pastor-Asurza ${ }^{2}$,

R. Perich-Campos ${ }^{2} .{ }^{1}$ Rheumatology; ${ }^{2}$ HNGAI, Lima, Peru

Background: Rapid Radiographic Progression (RRP) in Rheumatoid Arthritis (RA) patients predicts long-term disability (1), high related economic costs (2) and loss of working time (3). Detection of RRP predictors as a necessary tool for aggressive therapeutic interventions has been proved, but in Latin-American cohorts, no available data had been reported.

Objectives: To determine independent risk factors associated with RRP in a cohort of RA patients

Methods: A prospective analysis of RA Almenara cohort (January 2015-April 2016), 500 patients followed up with annual evaluations (background clinical/epidemiology, clinimetric, laboratory, health questionnaires and X-rays) who meet ACR 87/ACR-EULAR 2010 criteria's, older than 16 years at diagnosis,sign informed consent. Patients with overlap (except Sjögren), with active infections and/or pregnancy are excluded. Patients with at least two radiographs (baseline/final) were included. The X-rays were taken in a standardized protocol (each hand and foot). Joint damage was measured by Sharp-VDH (erosions, decreased joint space, and total scores). Radiographic Progression (RP) as a annual difference in Sharp-VDH score and RRP ( $>5$ units in RP) were determined. A blinded rheumatologist for the RA condition read all films. Associated factors were analyzed (gender, socioeconomic level, smoking, age at diagnosis, time disease, use of biological and non-biological DMARDs, DAS 28, current steroids, HAQ/functional capacity, RF and basal SharpVDH score). Diagnosis delay and CRP were included to analyze risk factors in the RRP group. Statistical analyzesTweedie regression models with logarithm link. SPSS v. 21.0 was used Results: 153 patients, 90.8\% women, middle low (37.9\%) and middle (35.3\%) the most prevalent socioeconomic status. Age at diagnosis was 46.06 (12.73) years, time disease 14.25 (10.26) years. DAS28 average: 4.51 (1.33). Basal Sharp VDH:104.53 (90.09), CRP: 9.77 (10.35) UI/L, RF: 352.49 (538.08) UI/L, ACPA: $563.64(782.2) \mathrm{Ul} / \mathrm{dL}$. PR annual rate was 7.64 (2.4 years of follow up), $94.8 \%$ increased damage and 74 patients $(48.36 \%$ ) had PRR. Most subjects (94.1\%) were using DMARDs but only $15(9.8 \%)$ biologicals. The mean dose of prednisone was $4.88(3.33) \mathrm{mg} / \mathrm{d}$. In the univariate analysis, only DMARDs was associated with $\mathrm{RP}(\mathrm{B}=50.8 ; \mathrm{Cl}=40.13-51.48, \mathrm{p}<0.001)$, remaining this association in the multivariate analysis $(B=50.56 ; \mathrm{Cl}=49.80-51.33, \mathrm{p}<0.001)$. In the multivariate analysis of RRP group, no variables was associated with risk and subjects with steroids use had less radiographic impairment $(B=0.859 ; \mathrm{Cl}$ $0.759-0,893, p=0.017$ ).

Conclusions: In this prospective study of an established RA cohort, a large proportion of patients had RRP and there was few percentage of biologic use. In the RRP subset only steroids use was a protective factor.

\section{References:}

[1] van den Broek M, Ann Rheum Dis. 2012;71(9):1530-3.

[2] Furneri. Clin Exp Rheumatol. 2012;30(4 Suppl 73): S72-84.

[3] Kavanaugh A. J Rheumatol. 2004;31(5):849-55. 
Disclosure of Interest: None declared

DOI: 10.1136/annrheumdis-2017-eular.3145

\section{AB0270 HOW DOES THE ACTIVITY OF RHEUMATOID ARTHRITIS EVOLVE WITHIN A COHORT OF RECENT ONSET PATIENTS WITH A 5-YEAR FOLLOW-UP?}

R. Jiménez Gasco, R. Ortega Castro, J. Calvo Gutierrez, P. Font Ugalde, A. Escudero Contreras, E. Collantes Estevez. Reumatología, Hospital Universitario Reina Sofia de Córdoba, Cordoba, Spain

Background: Rheumatoid arthritis (RA) is a chronic inflammatory joint disease affecting $0.5 \%$ of Spanish population. This disease results in a significant radiological and functional deterioration, decreasing the quality of life and increasing its mortality if an specific treatment is not applied. Although the radiological and functional deterioration progress slowly during the whole course of the disease, it has been proven that early and aggressive approach to the disease is important in order for its control because the final outcome can be improved with a close, intense and early follow-up.

Objectives: To describe the clinical characteristics and evolution during 5 years of disease activity in RA patients derived from a recent arthritis clinic.

Methods: A prospective longitudinal study was carried out of 154 patients diagnosed from 2003 to 2012. They included patients over 18 years old diagnosed with RA (ACR criteria 1987) and with 5 years of follow-up. Socio-demographic and clinical variables such as Rheumatoid factor (FR) and anti-citrullinated peptide antibodies (ACPA) or disease activity (DAS28-VSG) as well as treatment were assessed in those patients. Mean and standard deviation of quantitative variables and frequencies and percentages of qualitative variables were calculated. Proportions were compared using the Cochran $Q$ test statistic in order to compare differences between remission (determined by DAS-28<2.6) measured at 1 year, 2 years and 5 years from diagnosis. Data were analyzed using SPSS v17 program.

Results: Of the 154 patients, $66.2 \%$ were females with a mean age at diagnosis of $52.88 \pm 14.64$ years. Only $18.8 \%$ (29) patients were smokers; $67.5 \%$ (104) of patients were RF positive and $57 \%(88)$ of them were ACPA positive. Clinical remission measured by means of DAS 28-VSG $(<2.6)$ was achieved in 84 patients $(54.5 \%), 92$ patients $(59.7 \%)$ and 95 patients $(61.7 \%)$ after 1,2 and 5 years, respectively. Mean values of DAS 28 were 2.58 (2.02) at first year, $2.56(1.99)$ at two years and $2.59(2.02)$ at 5 years. Of the 154 patients, $108(78.8 \%)$ started treatment with monotherapy (mostly methotrexate) and after 5 years only 18 $(25.7 \%)$ patients were on biological treatment. No differences were found when remission was compared at first, second and 5 years of follow-up.

Subsequent comparison of two-to-two ratios among the three groups using $x^{2}$ contrast also indicated that there were no statistically significant differences between groups. However a tendency in data was observed, so that once patients had reached the remission at first year there was no increase in the number of them showing remission in the successive years of follow-up.

Conclusions: These results suggest that achieving an early control of the disease is of importance, since control of the disease becomes more difficult as the delay of the diagnosis increases.

References:

[1] Villaverde Garcia V, Balsa A, Carmona L, Sanmartí R, Maese J, Pascual

D, Ivorra J. What are patients with early rheumatoid arthritis like in Spain? Description of the PROAR cohort. Reumatología clínica.2009;5:115-120.

Disclosure of Interest: None declared

DOI: 10.1136/annrheumdis-2017-eular.6878

\section{AB0271 T2T ADHERENCE MEASUREMENT TOOL PERFORMANCE IN RHEUMATOID ARTHRITIS}

R. Garcia Salinas, M.P. Girard Bosch, M.V. Martire, P. Arturi, S. Magri. Hospital Italiano de la Plata, la Plata, Buenos Aires, Argentina

Background: The purpose of the T2T approach in RA is to achieve remission or LDA according to results from objective activity measurements. This strategy has proven clinical benefits, however objective adherence T2T measurement tools are lacked in daily practice.

Objectives: To evaluate the setting, usage of a T2T adherence measure: T2T70 and T2T100, and its association with sustained low disease activity (LDAS) as a measure of outcome.

Methods: Prospective study, consecutive patients with RA diagnosis (ACR/EULAR 2010) and follow-up between 1 and 24 months were included. Data from electronic medical record (EHR) were collected. Demographic variables, characteristics of the disease and treatment were recorded. The following T2T characteristics were defined and collected from each patient: number of visits, visits where treatment was adjusted, CDAI measurements, use of ultrasound to measure disease activity and achievement of LDA. Sustained LDA (LDAS) was defined when the patient had 2 or more records of that consecutive state of activity. Measures of adherence to T2T were defined as follows: T2T-70, when therapeutic decisions were accompanied by the measurement of activity by $70 \%$ and the interval between visits did not exceed 6 months; And T2T-100, when $100 \%$ of the decisions were accompanied with the activity measurement and the interval between each visit did not exceed 6 months. Statistical analysis: a descriptive analysis of the variables was performed and Chi2 test (categorical) and Student or MannWhitney test (continuous) were applied. For multivariate logistic regression analysis we considered as dependent variable LDAs.

Results: 96 patients were included, with a mean follow-up of 15 months (DS 7.8), equivalent to 120.6 patients/year. Eighty percent of the patients were women, mean age 53.7 years (SD 13), disease duration 36 months (RIC, 12-52), 64\% had early diagnosis, $85 \%$ and $75 \%$ positive For FR and ACPA, respectively. According to T2T characteristics, 526 visits were recorded, 270 were treatment adjustment and $208(78 \%)$ of them were performed according to the CDAl value. The frequency of LDAS was 20\% (IC95: 12-30). The frequency of T2T-70 compliance was $62.5 \%$ (IC95: 52-72) and T2T-100 was 42\% (IC95: 32-52). Compliance with T2T-70 and T2T-100 presented a statistically significant association to the achievement of LDAS in the uni and multivariate analysis ( $p: 0.000)$. Compliance with T2T-70 and T2T-100 was associated with a shorter time course of disease; And T2T-70 also showed association with early diagnosis.

Conclusions: T2T-70 and T2T-100 adherence were $62 \%$ and $42 \%$, respectively, patients who met these criteria reached more LDAS. The early diagnosis and shorter time to disease evolution at baseline were variables that were variables that were associated with more compliance of these tools.

Acknowledgements: Dra Josefina Marcos.

Disclosure of Interest: None declared

DOI: 10.1136/annrheumdis-2017-eular.3051

\section{AB0272 THE PERFORMANCE OF A SINGLE CENTRE INTERVENTIONAL CLINIC IN EARLY RHEUMATOID ARTHRITIS}

R. Jese, A. Ambrožič, N. Gašperšič, A. Hočevar, K. Perdan Pirkmajer, B. Lestan M. Pavič Nikolič, M. Plešivčnik Novljan, S. Praprotnik, Ž. Rotar, A. Šipek

Dolničar, D. Šuput Skvarča, M. Tomšič. Department of Rheumatology, University Medical Centre Ljubljana, Ljubljana, Slovenia

Background: In early rheumatoid arthritis (RA), first assessment by a rheumatologist and/or initiation of disease-modifying anti-rheumatic drugs (DMARD) within 12 weeks of symptom onset are associated with a significant benefit in long-term disease outcome.

Objectives: Our objective was to determine the proportion of patients with newly diagnosed RA in whom first rheumatology assessment and/or initiation of DMARD therapy was within the desired time frame.

Methods: A retrospective chart review of adult patients diagnosed with RA during years 2014 and 2015 was performed at the rheumatology department of an integrated secondary/tertiary teaching hospital that provides rheumatology services for a population of more than 500.000 residents. Potential cases were identified by searching the electronic medical records for ICD-10 codes M05.* and M06. Electronic and paper records of patients were then thoroughly reviewed. In addition to demographic and clinical data, dates were recorded for onset of inflammatory joint symptoms, referral to rheumatologist, initial assessment by a rheumatologist and initiation of DMARD therapy. The percentage of patients assessed by a rheumatologist and/or treated with a DMARD within 12 weeks of symptom onset and the median times for delay were then calculated.

Results: Between January 1st 2014 and December 31st 2015, 243 new cases of RA were identified at our Department of Rheumatology. Of those, 197 (81.1\%) were referred to our early interventional clinic. Within 12 weeks of symptom onset, $111(45.7 \%)$ new RA patients were examined by a rheumatologist and $87(35.8 \%)$ were started on DMARD therapy; the median time from symptom onset to consultation was 13.0 (IQR 4.6-27.8) weeks, median time from referral to consultation was 1 (IQR 1-3) days and median DMARD treatment delay was 15.7 (IQR 8.7-31.9) weeks.

Table 1. Demographic data, clinical history, and delays

Gender (female/male) (\%)

Age, years (median)

Patients fulfilling 2010 ACR/EULAR classification criteria for RA, N (\%)

DAS28 3v (mean \pm SD)

Erosive disease (plain radiographs) at first rheumatologist assessment, $\mathrm{N}(\%)$

Time from symptom onset to first rheumatologist assessment, weeks (median)

Time from referral to first rheumatologist assessment, weeks (median)

Time from symptom onset to glucocorticoid initiation, weeks (median)

Time from symptom onset to DMARD initiation, weeks (median) $183 / 60(75 / 25)$ $64.2($ IQR, 52.1-75.9) $228(93.8)$ $5.3 \pm 1.3$ 67 (31.5) 15.7 (IQR, 8.7-31.9)

Conclusions: $46 \%$ of new RA patients were assessed by a rheumatologist and $36 \%$ were treated with a DMARD within the recommended time frame of 12 weeks. Most of the treatment delay was due to the time elapsed between symptom onset and referral to a rheumatologist. These results substantiate the efficacy of our early interventional clinic in diagnosing and treating patients with early RA: despite the heavily protracted nationwide waiting times for first rheumatologist assessment and significantly (40\%) lower number of rheumatologists per capita compared to European Union average, the percentage of timely treated patients was comparable to recent reports.

Disclosure of Interest: None declared

DOI: 10.1136/annrheumdis-2017-eular.5276 